\title{
Biomedical Prospects for The Use of Stem Cells for The Treatment of Gliomas
}

\author{
Vladimir Kulchitsky*1 and Stanislav Koulchitsky ${ }^{2}$ \\ ${ }^{1}$ Institute of Physiology, National Academy of Sciences, Belarus \\ ${ }^{2}$ Institute of Physiology, University of Liège, Belgium
}

Received: May 23, 2018; Published: May 29, 2018

*Corresponding author: Vladimir Kulchitsky, Scientific Director, Institute of Physiology, National, Academy of Sciences of Belarus, 28 Akademicheskaya Street, Minsk 220072, Belarus

Abbreviations: MiRs: MicroRNAs; SCs: Stem Cells; TNF- $\alpha$ : Tumor Necrosis Factor

\section{Introduction}

Low efficiency of classic antitumor therapy initiates search for new ways of early diagnostics, prophylaxis and treatment of tumors. Specialists sometimes pay attention to extraordinary strategies based, for example, on the use of stem cells (SC) as specific biological agents aimed at destruction of malignant gliomas [1-3]. These technologies are the result of stem cells fundamental ability to migrate to brain tumors penetrating through blood-brain barrier [1]. Malignant gliomas have been chosen for analysis of effectiveness of cell technologies in oncology because they are one of the most fatal and do not respond to existing methods of antitumor treatment. It is quite often when deep tumor invasion into vital brain regions complicates total surgical elimination of gliomas.

Therefore, new additional treatment methods are important, for example, SCs which are comparatively easy modified in order to transfer therapeutic genes [2] and weaken immunoreactivity to SCs of patient's organism after their implantation [4]. It is considered that weakened immunoreactivity contributes to preservation of antitumor viruses in tumor tissue [5]. From this perspective, microRNAs (miRs) seem promising therapeutic agents in glioblastoma cells destruction [3]. Unfortunately, the question "which miRs are the most effective against glioblastoma?" still remains unanswered. On the other hand, separate retrospective studies in patients with recurrent high-grade glioma who received neural SC-mediated enzyme/prodrug gene therapy showed positive effects of such cell therapy [6].

\section{Stem cells and malignant glioma cells}

There is another one paradox in oncology: detection of identical Raman spectra of mesenchymal rat's SC and tumor cells of rat's C6 glioma [7]. It is quite unusual that the spectra of two types of undifferentiated cells - tumor (C6 glioma) and non-tumor ones (neural SC) match, and this unusualness enhances by evidences of identical biomarkers detection on their membranes, for example CD90 [8,9]. This evolutionary phenomenon requires explanation. Protective mechanisms of immune system are activated during formation of tumor tissue in the organism. It is known that antigen presentation is the main event in the development of immune response. Expression of CD28 antigen on T-cells is one of the key stages of the process. CD28 interacts with B7/BB1 ligands.

The process is modified by the plenty of signaling molecules, including heat shock proteins, cytokines, different subtypes of TollLike Receptors and mediators. Tumor-associated antigens also take part in anti-tumor reactions. SCs try to avoid immunological surveillance at each stage of these processes. Statistics demonstrates that tumor cells attained perfection in masking and phenotype changing in order to stand against protective immune reactions. Let us come with next situation. For example, protective elements of immune system detected CD90 on glioma cells. Dilemma arises for T-killers - to get rid of these suspicious elements or save them alive, because neural SCs also have the same biomarker. Let's assume that they decide to kill suspicious cells. But what of these cells were not tumor ones, but neural SCs? In this case reparative potential of nervous system decreases leading to progression of neurodestructive processes typical for, for example, Alzheimer's disease. But there is also positive effect - brain tumor does not develop. The opposite "decision" of immune system aimed at preservation of "unclear" cells similar to SCs may lead to manifestation of tumor process. 


\section{Contradictions in the technique of stem cells implanta- tion in brain tumors}

Neural and other type of SC show taxis to damaged tissues and tumor microenvironment. Various signaling substances including anti-inflammatory and angiogenic factors are expressed into these areas [10]. Activated astrocytes and microglial cells of peritumor edema zone initiate inflammatory process in glioma [11] that attracts mesenchymal SCs. Tumor necrosis factor (TNF- $\alpha$ ) contributes to increase of chemokine receptor expression in order to ease chemotactic invasion of mesenchymal SC [12]. Interaction between mesenchymal SC and elements of intercellular matrix is the key factor in implementation of SC migration process [13]. As mentioned before, plenty of factors influence taxis of SCs to tumor tissue. Further investigations are needed to unite these factors into complex mechanism of SCs migration and develop improved clinical protocols for SCs use as therapeutic agents for glioma treatment [14].

It should be kept in mind that mesenchymal SCs contribute to tumor growth by suppression of immune system [15] and malignant transformation of implanted mesenchymal SCs [16]. Therefore, conditions for interactions between mesenchymal SCs and tumor cells as well as potential risk of transformation of mesenchymal SCs into malignant neoplasms still remain unknown. The good news is that mesenchymal SCs transplantation to more than 1000 patients did not lead to tumor development in none of the cases [17]. Authors note [17] that infiltration of macrophages and granulocytes was much higher in tumors subjected to injection of mesenchymal SCs compared to intact ones. This testifies that mesenchymal SCs possess pro-inflammatory effects in such model.

\section{Conclusion}

It should be reminded that malignant gliomas are one of the most fatal tumors, and all existing treatment methods remain ineffective due to invasive growth and high risk of relapse. The therapy based on neural and mesenchymal SCs is promising because of positive results both in experiments and clinic. Collected data say for the use of SCs potential in combination with traditional surgical, chemotherapeutical, radiological and especially those techniques which are aimed at activation of immune system [18], delivery of metabolizing genes and/or oncolytic viruses [19].

\section{Acknowledgement}

This pooled analysis was funded by 000 "Synergy".

\section{References}

1. Aboody KS, Brown A, Rainov NG, Bower KA, Liu S, et al. (2000) Neural stem cells display extensive tropism for pathology in adult brain Evidence from intracranial gliomas. Proc Natl Acad Sci USA 97(23): 12846-12851.

2. Aboody KS, Najbauer J, Danks MK (2008) Stem and progenitor cellmediated tumor selective gene therapy. Gene Ther 15(10): 739-752.
3. Lang FM, Hossain A, Gumin J, Momin EN, Shimizu Y, et al. (2018) Mesenchymal stem cells as natural biofactories for exosomes carrying miR-124a in the treatment of gliomas. Neuro Oncol 20(3): 380-390.

4. Jones BJ, Mc Taggart SJ (2008) Immunosuppression by mesenchymal stromal cells: From culture to clinic. Exp Hematol 36(6): 733-741.

5. Power AT, Bell JC (2007) Cell-based delivery of oncolytic viruses: A new strategic alliance for a biological strike against cancer. Mol Ther 15(4): 660-665.

6. Sahoo P, Frankel P, Ressler J, Gutova M, Annala AJ, et al. (2018) Early Changes in Tumor Perfusion from T1-Weighted Dynamic ContrastEnhanced MRI following Neural Stem Cell-Mediated Therapy of Recurrent High-Grade Glioma Correlate with Overall Survival. Stem Cells Int 2018: 5312426.

7. Kulchitsky VA, Arzumanyan GM, Dosina MO, Mamatkulov KZ, Suziedelis $\mathrm{K}$, et al. (2016) Raman spectroscopy: comparing the "fingerprints" of C6 glioma and mesenchymal stem cells. J Stem Cells Regenerative Therapy (JSCRT) 1(1): 1-9.

8. Kumar A, Bhanja A, Bhattacharyya J, Jaganathan BG (2016) Multiple roles of CD90 in cancer. Tumour Biol 37(9): 11611-11622.

9. Yip S, Sabetrasekh R, Sidman RL, Snyder EY (2006) Neural stem cells as novel cancer therapeutic vehicles. Eur J Cancer 42(9): 1298-1308.

10. Birnbaum T, Roider J, Schankin CJ, Padovan CS, Schichor C, et al. (2007) Malignant gliomas actively recruit bone marrow stromal cells by secreting angiogenic cytokines. J Neurooncol 83(3): 241-247.

11. Spaeth E, Klopp A, Dembinski J, Andreeff M, Marini F (2008) Inflammation and tumor microenvironments: Defining the migratory itinerary of mesenchymal stem cells. Gene Ther 15(10): 730-738.

12. Egea V, von Baumgarten L, Schichor C, Berninger B, Popp T, et al. (2011) TNF- $\alpha$ respecifies human mesenchymal stem cells to a neural fate and promotes migration toward experimental glioma. Cell Death Differ 18(5): 853-863.

13. Ho IA, Chan KY, Ng WH, Guo CM, Hui KM, et al. (2009) Matrix metalloproteinase 1 is necessary for the migration of human bone marrow-derived mesenchymal stem cells toward human glioma. Stem Cells 27(6): 1366-1375.

14. Martinez Quintanilla J, Bhere D, Heidari P, He D, Mahmood U, et al. (2013) Therapeutic efficacy and fate of bimodal engineered stem cells in malignant brain tumors. Stem Cells 31(8): 1706-1714.

15. Djouad F, Plence P, Bony C, Tropel P, Apparailly F, et al. (2003) Immunosuppressive effect of mesenchymal stem cells favors tumor growth in allogeneic animals. Blood 102(10): 3837-3844.

16. Spaeth EL, Dembinski JL, Sasser AK, Watson K, Klopp A, et al. (2009) Mesenchymal stem cell transition to tumor-associated fibroblasts contributes to fibrovascular network expansion and tumor progression. PLoS One 4(4): e4992.

17. Klopp AH, Gupta A, Spaeth E, Andreeff M, Marini F 3rd (2011) Concise review: Dissecting a discrepancy in the literature: Do mesenchymal stem cells support or suppress tumor growth? Stem Cells 29(1): 11-19.

18. Kraśko JA, Žilionytė K, Darinskas A, Strioga M, Rjabceva S, et al. (2017) Bacterial ghosts as adjuvants in syngeneic tumour cell lysate-based anticancer vaccination in a murine lung carcinoma model. Oncol Reports 37(1): 171-178.

19. Namba H, Kawaji H, Yamasaki T (2016) Use of genetically engineered stem cells for glioma therapy. Oncol Lett 11(1): 9-15. 
(c) (P) This work is licensed under Creative

Submission Link: https://biomedres.us/submit-manuscript.php

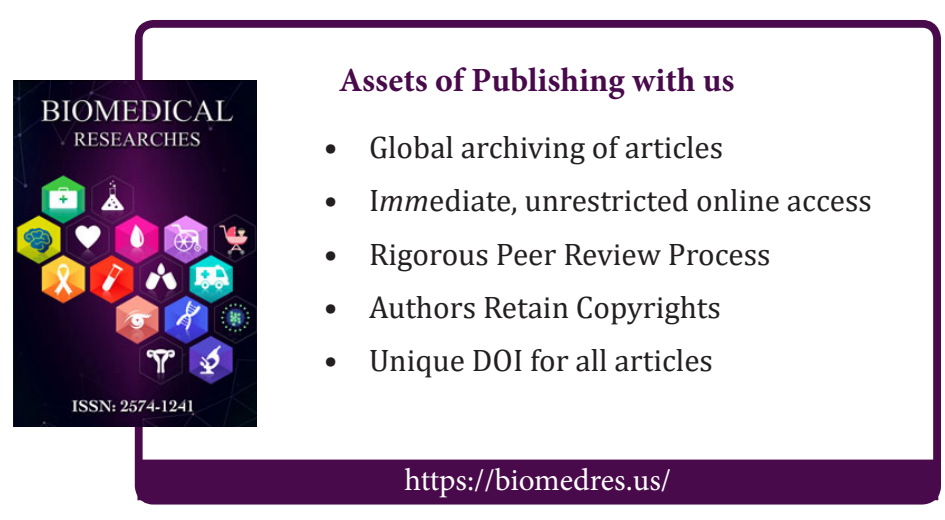

